\title{
根据步氏巨猿与伴生动物牙釉质稳定碳同位素分析 探讨其食性及栖息环境
}

\author{
赵凌霞 ${ }^{(12)}$ ，张立召 ${ }^{(12)(4)}$, 张福松 ${ }^{(3)}$, 吴新智 ${ }^{(2)}$ \\ (1) 中国科学院脊椎动物进化系统学重点实验室, 北京 100044; \\ (2) 中国科学院古脊椎动物与古人类研究所人类演化实验室, 北京 100044 ; \\ (3) 中国科学院地质与地球物理研究所, 岩石圈构造演化国家重点实验室稳定同位素实验室, 北京 100029; \\ (4) 中国科学院研究生院, 北京 100049 \\ E-mail: zhaolingxia@ivpp.ac.cn
}

2011-05-11 收稿, 2011-07-29 接受

现代古生物学和地层学国家重点实验室开放基金(103105)、国家自然科学基金(41072016)、科技部国际合作重点项目(2009DFB20580)和 科技基础性工作专项(2007FY110200)资助

\begin{abstract}
摘要 分析研究了湖北建始龙骨洞和广西柳城巨猿洞 8 枚巨猿牙齿及 9 种伴生哺乳动物 24 枚牙齿的釉质稳定碳同位素比例, $\delta^{13} \mathrm{C}$ 值(PDB)为 $-18.8 \%$ $-14.1 \%$ ，其中建始 4 个巨猿牙齿 的釉质 $\delta^{13} \mathrm{C}$ 值为 $-18.2 \%$ - 14.2\%o, 柳城 4 个巨猿牙齿釉质的 $\delta^{13} \mathrm{C}$ 值为 $-17.5 \%$ - 16.8\% 。 数 据结果表明巨猿及伴生动物群的食性均为纯 $\mathrm{C}_{3}$ 食性. 依据 $\mathrm{C}_{3}$ 植物的分布规律、相关地区植 被的 $\mathrm{C}_{3} / \mathrm{C}_{4}$ 植物组成、巨猿动物群和古植物孢粉等综合分析, 推测巨猿生活于 $\mathrm{C}_{3}$ 植物占优势 的植被环境, 应该是森林环境, 而非开阔环境. 巨猿的绝灭可能与栖息环境退缩恶化等因素 密切相关.
\end{abstract}

\section{关键词}

步氏巨猿

食性

稳定性碳同位素 栖息环境
食性和生态环境是人类起源、演化及适应性的关 键要素, 是古人类学研究的重要课题. 步氏巨猿 Gigantopithecus blacki 是最大的灵长类动物, 曾被认 为是人科成员或绝灭旁支 ${ }^{[1 \sim 4]}$, 发现于华南地区(图 1), 时代从早更新世至中更新世. 巨猿牙齿领骨硕大，形 态结构特化，其食性和生态环境备受关注，它对闸释 巨猿的演化和绝灭有重要意义.

关于巨猿的栖息环境前人有过推测, 主要有两 种意见: 一是认为巨猿生存于比较开阔的草原环境 或者开阔的稀树林地; 另一种则认为生活于森林环 境. 裴文中 ${ }^{[5]}$ 根据广西柳城巨猿动物群, 推测当时巨 猿洞附近生长着茂密的森林, 水流相当多, 气候温暖 湿润, 和现在广东、广西、云南差不多. 湖北建始巨 猿洞动物群所反映的环境是亚热带森林环境, 孢粉 组成也反映出森林植被景观 ${ }^{[6,7]}$. 有国外学者根据巨
猿牙齿和领骨的解剖结构特点, 如硕大的项齿和粗 壮的领骨, 推测巨猿体型硕大, 主要在地面活动和受 食, 并具有特别强烈的咀嚼活动, 适合于开阔草原环 境, 类似现在生活在埃塞俄比亚的狒狒. 印度北部发 现的另一种晚中新世巨猿 Gigantopithecus bilaspurensis 伴生动物及沉积学研究显示巨猿生活于较开阔 的草原环境 ${ }^{[8]}$.

运用牙齿釉质稳定碳同位素分析方法可以复原 古人类的食性和生态环境. 其主要原理: 植物因为光 合作用途径不同而分别出 $\mathrm{C}_{3}$ 植物、 $\mathrm{C}_{4}$ 植物和 $\mathrm{CAM}$ 植物. CAM 植物在自然界中很少见, 多数肉质植物 属于此类. $\mathrm{C}_{3}$ 和 $\mathrm{C}_{4}$ 植物具有显著不同的 ${ }^{13} \mathrm{C} /{ }^{12} \mathrm{C}$ 比例 (国际上通用 $\delta^{13} \mathrm{C}$ 值表示 $\delta^{13} \mathrm{C}=\left(R_{\text {sample }} / R_{\text {标准 }}-1\right) \times 1000$, $R={ }^{13} \mathrm{C} /{ }^{12} \mathrm{C}$, 标准样品是美国北卡罗纳州白严系的 Pee Dee Formation 的拟箭石, 即 PDB 标准), $\mathrm{C}_{3}$ 和 $\mathrm{C}_{4}$ 植物 


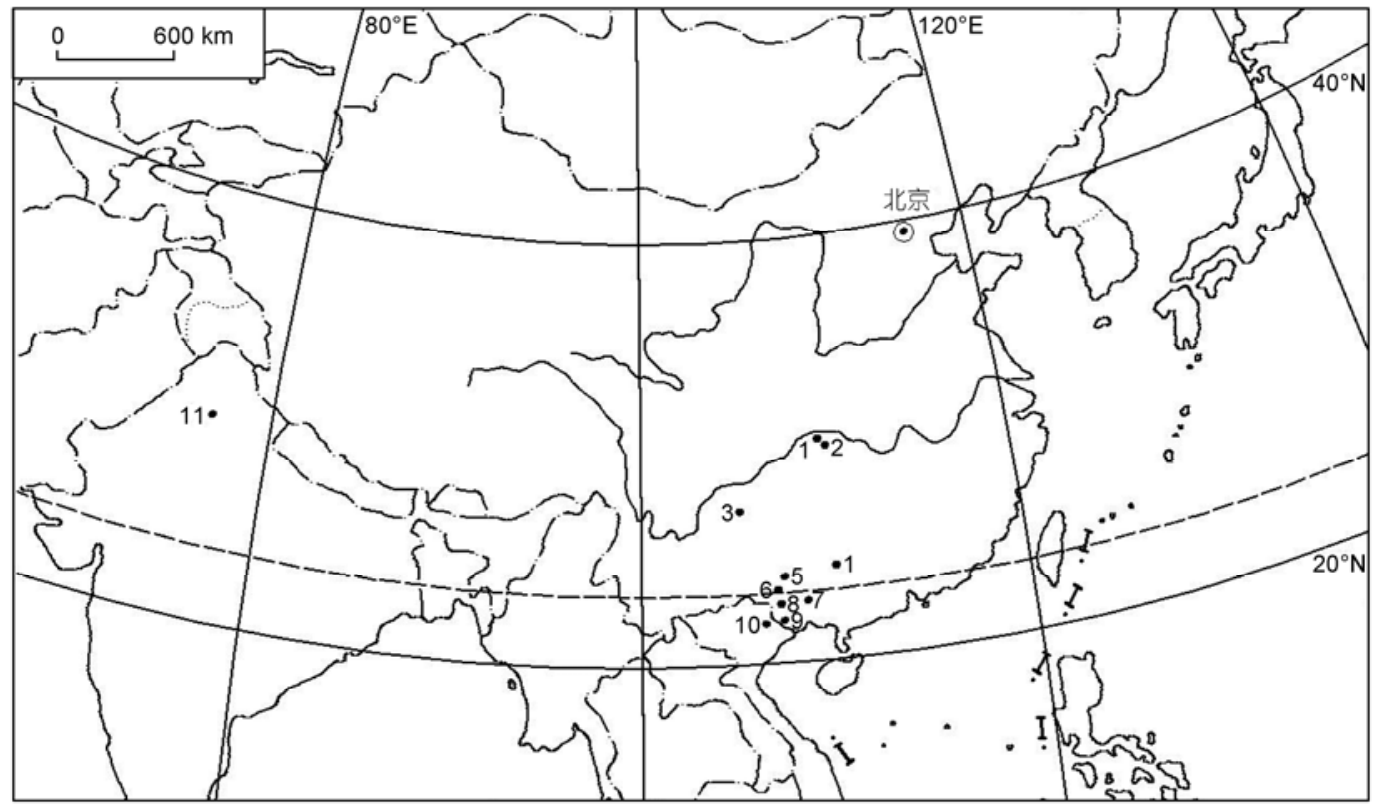

图 1 巨猿化石点分布图

1 , 巫山龙骨坡; 2 , 建始龙骨洞; 3 , 毕节扒耳岩; 4 , 柳城巨猿洞; 5 巴马弄莫山; 6 , 田东么会洞; 7 , 武鸣拉利山; 8 , 大新黑洞; 9 , 崇左三合大洞; 10, 越南 Tham Khuyen; 11, 印度 Haritalyangar

的 $\delta^{13} \mathrm{C}$ 值变化范围分别为 $-35 \%$ - $22 \%$ 和 $-16 \%$ $-8 \%$. $85 \%$ 的陆生植物都属于 $\mathrm{C}_{3}$ 植物，包括乔木、大 多数灌木、高纬度或高海拔或温凉季节生长的草本植 物; 大约 $10 \%$ 的陆生植物属于 $\mathrm{C}_{4}$ 植物, 现代热带和 亚热带的草本植物以 $\mathrm{C}_{4}$ 植物占优势. 经过食物链, 动物牙齿釉质稳定碳同位素比例 $\delta^{13} \mathrm{C}$ 可反映初级食 物中的 $\mathrm{C}_{3}$ 和 $\mathrm{C}_{4}$ 植物比例 ${ }^{[9]}$. 研究发现, 牙齿釉质在 埋藏过程中, 化学性质稳定, 其中的结构性碳酸盐几 乎不受成岩作用影响, 是了解远古化石物种食性及 生态环境的可靠记录 ${ }^{[10,11]}$. 因此, 牙齿釉质稳定碳同 位素比例分析方法已经应用于古人类食性分析、古环 境复原及环境演变等重要问题的探索中, 尤其是非 洲早期人类化石的研究 ${ }^{[12 ~ 21]}$. 本文分析研究了湖北 建始龙骨洞和广西柳城巨猿洞的巨猿及伴生动物群 牙齿釉质稳定性碳同位素比例，据此复原巨猿的食 性、栖息环境, 进而分析巨猿的绝灭问题.

\section{1 材料和方法}

(i) 研究材料及化石点. 主要研究材料出自湖 北建始高坪龙骨洞，包括 4 枚巨猿牙齿, 24 枚哺乳动 物牙齿. 另外 4 枚巨猿牙齿出自广西柳城巨猿洞.

建始高坪龙骨洞是我国重要的早期人类化石点,
该化石点从 1970 2000 年几次发掘出土巨猿牙齿化 石上百枚, 同时发现大量哺乳动物化石, 尤其是发现 早期人类化石，可能属于“南方古猿”, ${ }^{[22]}$ 或“魁人”, 柳城巨猿洞是巨猿材料最丰富的早更新世巨猿化石 点, 发现 3 个巨猿下领骨和上千枚牙齿, 巨猿生物特 征及相关问题主要基于这个地点的系统研究, 柳城 巨猿动物群是华南早更新世的代表性动物群.

8 枚巨猿牙齿标本均为残破牙齿, 但保存部分可 以鉴定是巨猿牙齿. 24 枚哺乳动物牙齿材料均来自 建始龙骨洞, 包括猪(Sus sp.)、丽牛(Leptobos sp.)、鹿 (Cervus sp.), 马(Equus sp.)、犀(Rhinoceros sinensis)、 貘(Tapirus sinensis)、粗壮瓺狗(Pachycrocuta licenti)、 熊(Ursus sp.)、大熊猫(Ailuropoda wulingshanensis). 标本编号及详细信息见表 1 .

(ii) 技术路线与方法. 样品制备过程: 将牙齿 釉质剥离下来, 表面污垢及内层齿质残存清除干净, 研磨成粉末. 将釉质粉末浸泡在 $5 \%$ 次氯酸钠溶液中 反应 $12 \mathrm{~h}$, 目的是除去样品中可能黏附的细菌蛋白 和腐殖酸盐. 蒸馏水冲洗过滤后, 将釉质粉末浸泡于 $6 \%$ 的醋酸中反应 $12 \mathrm{~h}$, 目的是除掉成岩过程中产生 的次生性碳酸盐, 以消除成岩作用的影响. 蒸馏水冲 洗过滤后, 烘干得釉质粉末样品. 
表 1 牙齿釉质稳定碳同位素测定结果

\begin{tabular}{|c|c|c|c|c|c|}
\hline 种类 & 样品号 & 牙齿鉴定 & 地点层位 & $\delta^{13} \mathrm{C}(\% o)$ & $\delta^{13} \mathrm{C}$ 平均值 \\
\hline \multicolumn{6}{|l|}{ 广西柳城巨猿洞 } \\
\hline Gigantopithecus blacki & 19 & 下臼齿 & $5704 \mathrm{C}$ & -17.5 & $-17.3 \pm 0.3$ \\
\hline Gigantopithecus blacki & 20 & 下臼齿 & $5704 \mathrm{~B}$ & -17.3 & \\
\hline Gigantopithecus blacki & 21 & 上臿齿 & $5704 \mathrm{C}$ & -17.5 & \\
\hline Gigantopithecus blacki & 22 & 下兒齿 & $5704 \mathrm{C}$ & -16.8 & \\
\hline \multicolumn{6}{|l|}{ 湖北建始龙骨洞 } \\
\hline Gigantopithecus blacki & 23 & 上毀齿 & 东洞口第 11 层 & -17.2 & $-16.4 \pm 1.8$ \\
\hline Gigantopithecus blacki & 24 & 下 P3 & 东洞口第 11 层 & -15.9 & \\
\hline Gigantopithecus blacki & 25 & 上兒齿 & 西主洞第 4 层 & -18.2 & \\
\hline Gigantopithecus blacki & 26 & 下兒齿 & 西主洞第 7 层 & -14.2 & \\
\hline \multirow[t]{3}{*}{ Leptobos sp. } & $1 \mathrm{~A}^{\mathrm{a})}$ & 下 P3 & 东洞口第 11 层 & -15.8 & $-15.9 \pm 0.8$ \\
\hline & $1 \mathrm{~B}$ & & & -15.7 & \\
\hline & $1 \mathrm{C}$ & & & -15.8 & \\
\hline Leptobos sp. & 2 & 下 M3 & 同上 & -15.4 & \\
\hline Leptobos sp. & 3 & 上 $\mathrm{M} 3$ & 同上 & -17.1 & \\
\hline Leptobos sp. & 4 & 上前臼齿 & 同上 & -15.3 & \\
\hline Cervus sp. & 5 & 下 M3 & 同上 & -16.8 & $-16.7 \pm 1.2$ \\
\hline Cervus sp. & 6 & 下 M3 & 同上 & -17.8 & \\
\hline Cervus sp. & 7 & 上 $\mathrm{M} 3$ & 同上 & -15.5 & \\
\hline Tapirus sinensis & 8 & 下兒齿 & 同上 & -16.6 & $-16.7 \pm 0.7$ \\
\hline \multirow[t]{2}{*}{ Tapirus sinensis } & $9 \mathrm{~A}$ & 下兒齿 & 同上 & -17.6 & \\
\hline & $9 \mathrm{~B}$ & & & -17.7 & \\
\hline Tapirus sinensis & 10 & 上舁齿 & 同上 & -16.3 & \\
\hline Tapirus sinensis & 11 & 下帠齿 & 同上 & -16.1 & \\
\hline Rhinoceros sinensis & 12 & 上 M1 & 同上 & -14.4 & $-15.2 \pm 0.6$ \\
\hline Rhinoceros sinensis & 13 & 下 M3 & 同上 & -15.8 & \\
\hline Rhinoceros sinensis & 14 & 下 M1 & 同上 & -14.9 & \\
\hline Rhinoceros sinensis & 15 & 上 $\mathrm{M} 3$ & 同上 & -15.8 & \\
\hline \multirow[t]{2}{*}{ Rhinoceros sinensis } & $32 \mathrm{~A}$ & 下兒齿 & 同上 & -15.4 & \\
\hline & $32 \mathrm{~B}$ & & & -15.4 & \\
\hline Pachycrocuta licenti & 16 & 前臼齿 & 同上 & -14.1 & -14.1 \\
\hline Ursus sp. & 17 & 臼齿 & 同上 & -15.9 & -15.9 \\
\hline \multirow{2}{*}{$\begin{array}{l}\text { Ailuropoda } \\
\text { wulingshanensis }\end{array}$} & $18 \mathrm{~A}$ & 臼齿 & 同上 & -18.3 & -18.3 \\
\hline & 18B & & & -18.3 & \\
\hline \multirow[t]{2}{*}{ Equus sp. } & $27 \mathrm{~A}$ & 下的齿 & 同上 & -18.8 & $-18.0 \pm 0.7$ \\
\hline & $27 \mathrm{~B}$ & & & -18.8 & \\
\hline \multirow[t]{2}{*}{ Equus sp. } & $28 \mathrm{~A}$ & 上前臼齿 & 同上 & -17.5 & \\
\hline & $28 \mathrm{~B}$ & & & -17.6 & \\
\hline \multirow[t]{2}{*}{ Equus sp. } & $29 \mathrm{~A}$ & 下臼齿 & 同上 & -18.4 & \\
\hline & $29 B$ & & & -18.4 & \\
\hline \multirow[t]{2}{*}{ Equus sp. } & $30 \mathrm{~A}$ & 下的齿 & 同上 & -17.3 & \\
\hline & $30 \mathrm{~B}$ & & & -17.3 & \\
\hline \multirow[t]{2}{*}{ Sus sp. } & $31 \mathrm{~A}$ & 下兒齿 & 同上 & -16.0 & -16.1 \\
\hline & $31 \mathrm{~B}$ & & & -16.1 & \\
\hline
\end{tabular}

a) 同一编号下的 A, B, C 代表同一个牙齿标本的釉质粉末平行样品 
稳定碳同位素测定：在中国科学院地质与地球 物理研究所岩石圈构造演化国家重点实验室稳定同 位素实验室完成. 用磷酸法制备二氧化碳气体. MAT252 型质谱仪测定二氧化碳的碳氧同位素比例, 以 PDB 为标准, 分析误差小于 $0.1 \%$ 。

\section{2 结果与讨论}

\section{1 釉质稳定碳同位素比例测定结果}

共制备了 32 个牙齿的釉质粉末样品, 为了检验 测试数据的可靠性, 对其中 9 个样品分别做了 2 3 平 行样, 共计测定了 42 个釉质粉末样品, 稳定碳同位素 比例 $\delta^{13} \mathrm{C}$ 见表 1 .

\section{2 巨猿的食性与栖息环境}

32 个牙齿釉质样品中, 食草动物马的 $\delta^{13} \mathrm{C}$ 值最 低为 $-18.8 \%$ ( 27 号样品), 食肉动物镾狗的 $\delta^{13} \mathrm{C}$ 值最 高为 $-14.1 \%$ ( $(16$ 号样品). 其他食草动物、吃嫩叶动 物、杂食动物及食肉动物的 $\delta^{13} \mathrm{C}$ 值介于其间. 建始龙 骨洞巨猿 $\delta^{13} \mathrm{C}$ 值为 $-18.2 \%$ - $14.2 \%$, 变异范围与其 伴生动物群的变异范围重叠. 柳城巨猿洞巨猿 $\delta^{13} \mathrm{C}$ 值为 $-17.5 \%$ - $16.8 \%$, 变异幅度较小. 8 个巨猿牙齿 釉质 $\delta^{13} \mathrm{C}$ 平均值为 $-16.8 \%$. 如果考虑动物牙齿釉质 与植物之间的 $\delta^{13} \mathrm{C}$ 富集关系, 即哺乳动物牙齿釉质 的 $\delta^{13} \mathrm{C}$ 值比其所吃植物的 $\delta^{13} \mathrm{C}$ 高 $14 \%{ }^{[23]}$, 那么所 有测试动物的食物链初级来源—植物 $\delta^{13} \mathrm{C}$ 变异范 围为 $-32.8 \%$ $-28.1 \%$, 这个数值完全落在 $\mathrm{C}_{3}$ 植物 $\delta^{13} \mathrm{C}$ 变异范围内 $\left(-35 \%\right.$ - 22\%o), 远离 $\mathrm{C}_{4}$ 植物的 $\delta^{13} \mathrm{C}$ 变异范围 $\left(-16 \%\right.$ - $8 \%$ ) , 也没有落在 $\mathrm{C}_{3}$ 植物和 $\mathrm{C}_{4}$ 植 物二者 $\delta^{13} \mathrm{C}$ 值之间的区域(-22\%o -16\%o), 说明巨猿 动物群, 不论是巨猿、还是典型食草动物 (如马、丽 牛), 或着吃嫩叶动物 (如貘、鹿), 无一例外地以 $\mathrm{C}_{3}$ 植物为食, 即便是食肉动物瓺狗和熊, 其猎物也是 $\mathrm{C}_{3}$ 食性. 因此巨猿及伴生大型哺乳动物的生态环境 应该是 $\mathrm{C}_{3}$ 植物占优势的植被环境.

依据 $\mathrm{C}_{3}$ 和 $\mathrm{C}_{4}$ 植物种类及分布规律, 可以对建始 和柳城巨猿的栖息环境进行分析判断. $\mathrm{C}_{3}$ 和 $\mathrm{C}_{4}$ 植物 的分布与纬度、海拔、温度、光照等因素有关. $C_{3}$ 植 物占绝对优势的植被环境分两种情况, 一是茂密的 森林环境, 另一种可能是寒冷或温凉气候下的开阔 稀树草原环境.

从现代植物区系划分看, 建始龙骨洞所在的鄂
西三峡地区属于亚热带森林区系. 就植被组成而言, 海拔 $800 \mathrm{~m}$ 以下的低山区, 多为常绿落叶混交林和针 阔叶混交林; 海拔 1500 1700 m 的山地, 以落叶、阔 叶和灌丛林为主; 海拔 $1700 \mathrm{~m}$ 以上开始向灌丛草甸 植被过渡. 建始龙骨洞所在的山坡, 是一个海拔只有 $794 \mathrm{~m}$ 的石灰岩小山丘, 属于峰丛地貌, 东洞口的海 拔高度约 $738 \mathrm{~m}$. 龙骨洞周围的现代植被, 基本上是 常绿阔叶林和针阔混交林, 表现出亚热带中、低山植 被景观. 调查发现中国 $\mathrm{C}_{4}$ 植物具有广阔的地理分布 特点, 尤其是在中亚热带和南亚热带 $\mathrm{C}_{4}$ 植物数量最 多 ${ }^{[24]}$, 以禾本科占优势. 三峡地区现代植被 $\mathrm{C}_{3}$ 和 $\mathrm{C}_{4}$ 类型的调查分析 ${ }^{[25]}$, 发现 75 种 $\mathrm{C}_{4}$ 植物, 仅占该区植 物种类总数的 $2.5 \%$, 其中 54 种禾本科 $\mathrm{C}_{4}$ 草类植物占 该地区全部草类植物的 $36 \%, 95 \%$ 的 $\mathrm{C}_{4}$ 种类可以在海 拔 500 800 m 的高度出现. 广东鼎湖山自然保护区 $\left(23^{\circ} 08^{\prime} \mathrm{N}, 112^{\circ} 35^{\prime} \mathrm{E}\right)$ 是一个典型的亚热带季风常绿阔 叶森林区, 至少 400 年来没有受到人类活动的影响. Ehleringer 等人 ${ }^{[26]}$ 对该区 128 种最常见植物的调查分 析, $73 \%$ 为 $\mathrm{C}_{3}$ 植物, $26 \%$ 为 $\mathrm{C}_{4}$ 植物, 只有 1 种植物是 少见的景天酸代谢途径的 CAM 植物. $\mathrm{C}_{4}$ 植物全都生 长在相对开阔的环境中, 是一些草类, 而在密闭的森 林环境和中间型环境中没有发现 $\mathrm{C}_{4}$ 植物. 基于建始 龙骨洞 $\left(30^{\circ} 40^{\prime} \mathrm{N}, 110^{\circ} 05^{\prime} \mathrm{E}\right.$, 洞底海拔高度 $\left.740 \mathrm{~m}\right)$ 和 柳城巨猿洞 $\left(24^{\circ} 40^{\prime} \mathrm{N}, 109^{\circ} 15^{\prime} \mathrm{E}\right.$, 海拔高度约 $\left.200 \mathrm{~m}\right)$ 所在的纬度和海拔高度, 假设当时有开阔的稀树草 原环境, 则应该含有比较丰富的 $\mathrm{C}_{4}$ 草本植物, 这样 的植被环境应该反映在食草动物的釉质碳同位素结 果中, 特别是典型的食草类动物马、牛类的釉质碳同 位素比例中. 可结果恰恰相反, 和其他所有动物一样, 建始马牛类的食物显示纯 $\mathrm{C}_{3}$ 植物. 因此, 建始和柳 城巨猿及伴生动物群 $\delta^{13} \mathrm{C}$ 值显示出完全的 $\mathrm{C}_{3}$ 植物, 意味着其生态环境是比较茂密的森林环境.

巨猿牙齿釉质稳定碳同位素结果所反映的森林 环境, 与动物群组合特征、古植物狍粉分析结果相符 合. 建始龙骨洞动物群, 不论是小哺乳动物还是大哺 乳动物, 都反映出以亚热带森林为主的生态环境 ${ }^{[7]}$. 东洞口 A 剖面的狍粉结果显示 ${ }^{[27]}$ : 乔木花粉占绝对 优势 76\% 80\%, 其次偋类植物占 13\% 16\%, 而草本 植物和灌木花粉只有 6\% 7\%. 显然是一种森林植被 景观. 柳城巨猿洞, 还有其他巨猿化石点, 如贵州毕 节扒耳岩、广西三合大洞等的巨猿动物群均反映了亚 热带森林环境. 时代与柳城、建始巨猿动物群相近的 
元谋动物群则不然, 都属于早更新世, 同样是食草动 物, 马的釉质碳同位素结果显示其食物中含有相当 比例的 $\mathrm{C}_{4}$ 植物, 可高达 $70 \%$, 意味着比较开阔的生 态环境 ${ }^{[28]}$.

综上, 根据巨猿牙釉质稳定碳同位素分析结果 以及化石点所在地区纬度、海拔、伴生动植物群及现 代植被等综合分析, 推断建始和柳城巨猿的栖息环 境是茂密的森林环境, 而非开阔的稀树草原环境.

Ciochon 等人 ${ }^{[29]}$ 观察研究了 4 枚巨猿牙齿上的植 硅石, 发现既有来自草本植物的植硅石, 也有来自果 实的植硅石, 认为巨猿食物包含草类和果实等多种 来源. Daegling 和 Grine ${ }^{[30]}$ 观察研究了巨猿牙齿微磨 痕, 认为其特征与普通黑猩猩最接近, 推断巨猿食性 以果实为主. 从巨猿高的龊齿率 ${ }^{[1,31,32]}$, 推断巨猿食 物中碳水化合物或糖分含量高. 从巨猿牙齿结构、釉 质厚度、牙齿磨耗和下领结构看, 推断巨猿食物比较 坚硬需要强大的咀嚼研磨. 一般来说同一种动物 $\delta^{13} \mathrm{C}$ 值分布比较集中, 但是建始巨猿的 $\delta^{13} \mathrm{C}$ 值有较 大的变异范围, 几乎涵盖了整个动物群的 $\delta^{13} \mathrm{C}$ 值变 异范围. 是否意味着巨猿的食谱可能较其他动物的 更宽些, 从树冠顶部的水果和树叶, 到树冠下和树冠 之间的灌木、草类及根茎等. 但是柳城巨猿的 $\delta^{13} \mathrm{C}$ 值 变异范围又很小. 由于样本量小, 这些推断还需要进 一步验证.

\section{3 巨猿与其他猿类的比较及其绝灭问题}

巨猿以纯 $\mathrm{C}_{3}$ 植物为食, 生活于森林环境, 这与
现代 3 种大型类人猿相似. 相比之下，与建始、柳城巨 猿时代相近的非洲早期人类则具有适应开阔环境的能 力, 并反映在牙齿釉质稳定碳同位素结果中. 从图 2 可以看出巨猿与非洲 3 种早期人类牙齿釉质稳定碳同 位素 $\delta^{13} \mathrm{C}$ 分布范围和平均值有显著差异. 非洲早期人 类的 $\delta^{13} \mathrm{C}$ 值明显偏高, 变异范围与巨猿没有重叠, 显 然脱离纯 $\mathrm{C}_{3}$ 食物的分布范围, 移向 $\mathrm{C}_{3}$ 和 $\mathrm{C}_{4}$ 混合食性 的分布范围. 南非 Makapansgat ${ }^{[14]}$ 和 Sterkfontein ${ }^{[15,17]}$ 的南方古猿非洲种 Australopithecus africanus 釉质 $\delta^{13} \mathrm{C}$ 分析显示, $\mathrm{C}_{4}$ 食物比例可高达 $40 \%$, 且不同个体 之间存在比较宽的变异范围, 说明 Australopithecus africanus 可以利用广泛种类的食物资源. 同样 Swartkrans 傍人粗壮种 Paranthropus robustus 食物中 也有相当比例的 $\mathrm{C}_{4}$ 食物, 占 $35 \%{ }^{[12,15]}$. 东非傍人鲍 氏种 Paranthropus boisei 情况更甚, $\mathrm{C}_{4}$ 食物比例甚至 高达 $80 \%^{[16,18]}$. 利用 $\mathrm{C}_{4}$ 植物资源, 意味着南方古猿 可以生活在开阔的林地或稀树草原环境中. LeeThorp 等人 ${ }^{[13]}$ 提出 $\mathrm{C}_{4}$ 食物的摄人可能是人类演化进 程中一个标志性转变.

但是时代更早的地猿始祖种牙齿釉质碳同位素 分析显示：地猿的食性与南方古猿区分明显，主要以 $\mathrm{C}_{3}$ 植物为食, 结合伴生动物群组合特征, 地猿主要 栖息于森林环境，而非南方古猿更加开阔的生态环 境 ${ }^{[33]}$. 这一结果似乎提示早期人类的解剖和行为特 征, 如直立行走并非是应对开阔热带稀树草原或镶 嵌环境情况下演化而来，而是在密林中已经演化出 这些特征, 并延续到南方古猿出现之时. 巨猿是否属

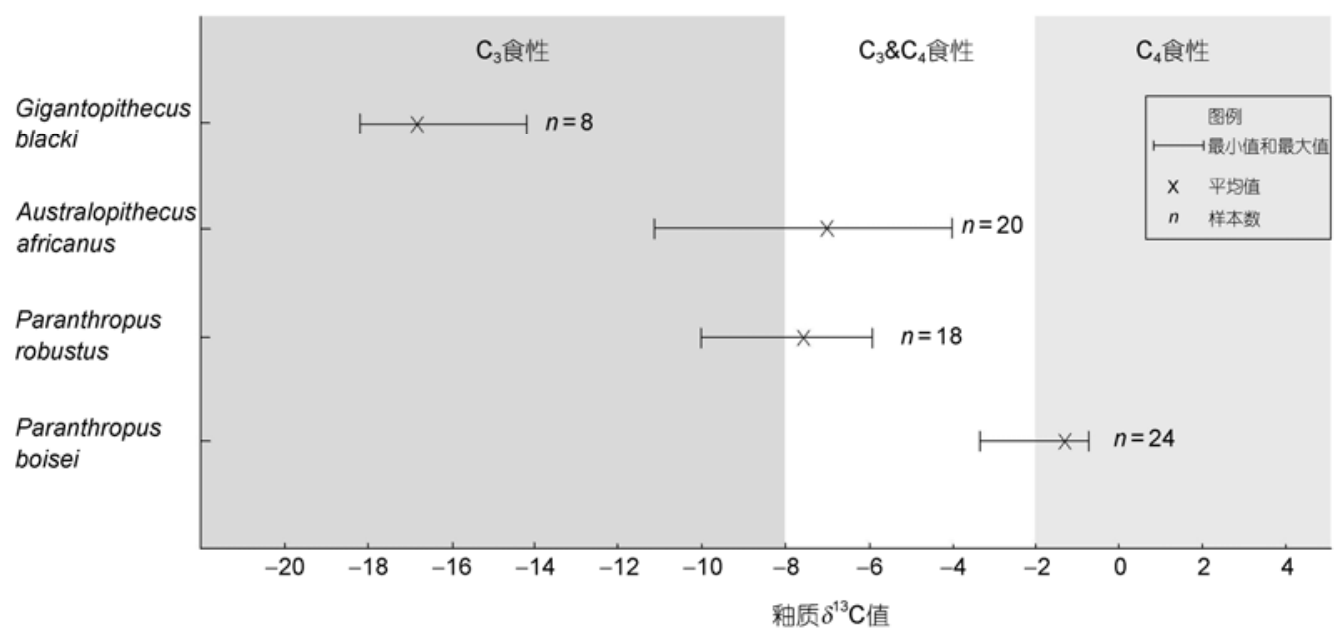

图 2 巨猿与非洲早期人类牙齿釉质 $\delta^{13} \mathrm{C}$ 及食性比较 
于早期人类, 是否具有直立行走的行为方式, 目前的 化石证据还不能回答这一问题. 虽然巨猿牙齿结构 显示出巨猿有些特征与人类相似, 如相对较小门齿 和犬齿, 下第三前自齿为双尖型，臼齿牙尖排列模式 及厚的釉质等，但不同的是，目前的证据显示巨猿的 栖息环境仅局限于森林环境, 而不同于人类生存环 境的多样性, 这也可能是巨猿绝灭的重要因素.

步氏巨猿曾经广泛分布于我国华南地区，什么 原因导致它最终绝灭? 目前广西发现的巨猿化石点 最多, 时代从早更新世延续至中更新世, 另外在鄂西 三峡地区、贵州毕节也发现巨猿化石，但时代均为早 更新世, 似乎提示巨猿从早更新世到中更新世的分 布范围在退缩, 这可能与更新世气候环境巨变有关. 童国榜等人 ${ }^{[34]}$ 分析了中国更新世孢粉植物群记录, 160 万年至 80 万年之间狍粉植物群演变表明, 早更 新世晚期至中更新世早期是第四纪环境发生巨变的 时期, 这与青藏高原大幅度隆升, 全球冰期、间冰期 气候冷暖交替进一步加剧相关联. 巨猿的栖息环境 势必受到影响, 进而影响巨猿的生存繁衍. 另外, 从 现生的两种亚洲猿类, 即猩猩和长臂猿的地史分布 和现状可以得到一些启示. 猩猩是一种大型的树栖 猿类, 现生活于印度尼西亚的苏门答腊和加里曼丹 岛上, 濒于绝灭境地. 在 1900 年, 这两个岛上的猩猩 总数估计约有 30 万只. 随着森林退化、人类活动影响、 栖息环境丧失, 到 1997 年猩猩总数减少到 2 万 7 千多 只, 相当于 1900 年的 $9 \%{ }^{[35]}$. 但更新世的猩猩化石分 布于南亚和东南亚广大地区，在华南地区从更新世早 期到更新世晚期都有很多猩猩化石发现. 猩猩是现生 哺乳动物中生长速率和繁殖力最低的物种, 母体照顾 子代一起生活要 6 7 年, 生殖间隔长达 8 年以上, 栖 息环境破坏会严重威胁其生存繁殖. 长臂猿是小型猿 类, 是东南亚热带、亚热带的特有动物. 历史时期长臂
猿曾广泛分布在我国南部大部分省区. 自公元 4 世纪 以来, 它们的分布发生了很大变化. 分布区由北到 南、从东到西急剧缩小, 现在黑长臂猿缩小到只在海 南岛、云南南部和越南北部, 为高度濒危的灵长类动 物. 造成黑长臂猿濒危的主要原因是热带和亚热带 原始森林的被破坏和缩小、人类活动的干扰使生境破 碎和恶化、过度猎捕和长臂猿自身的生物学弱点 ${ }^{[36]}$.

根据牙齿生长发育特征, 推测步氏巨猿幼儿生 长期长, 至少达到现代大猿的水平, 繁殖力低, 生殖 间隔长 ${ }^{[37]}$. 从牙齿和下领特点及体重估计, 巨猿体 型庞大. 牙齿高度磨耗、高发的龋病率及釉质发育不 良，提示巨猿食性特化并存在营养不良问题. 因此作 者推测, 随着更新世气候环境变化, 步氏巨猿的生存 环境可能不断恶化或退缩，同时巨猿自身的生物特 性和生活习性特化, 如繁殖力低下、体型庞大需要大 量食物、食性特化及营养不良, 对气候环境变化敏感 等等不利因素, 加上人类活动严重压力, 是其走向绝 灭的重要原因. 步氏巨猿与猩猩和长臂猿比较, 适应 性可能最差, 长臂猿在云南和海南现仍有分布, 猩猩 在晚更新世仍然广泛地分布于我国西南地区，只是 到了全新世才退缩到印尼岛上. 巨猿从早更新世到 中更新世, 分布范围大大向南退缩, 到晚更新世已完 全绝迹.

\section{3 结论}

通过建始和柳城巨猿及动物群牙齿釉质稳定性 碳同位素分析，可以得到以下认识：(1) 步氏巨猿的 食性是纯 $\mathrm{C}_{3}$ 食性. (2) 稳定性碳同位素结果支持步氏 巨猿的栖息环境是比较茂密的森林环境，而非开阔 的稀树草原环境. (3) 更新世气候环境剧烈波动, 步 氏巨猿的栖息环境可能不断恶化退缩，是其走向绝 灭的重要原因.

\section{参考文献}

1 吴汝康. 巨猿下领骨和牙齿研究. 中国古生物志新丁种, 1962, 11: 1-94

2 Weidenrich F. Giant early man from Java and South China. Anthrop Papers Amer Mus Nat Hist, 1945, 40: 1-134

3 Weidenrich F. Apes, Giants and Man. Chicago: The University of Chicago Press, 1946. 47-66

4 Frayer D W. Gigantopithecus and its relationship to Australopitheus. Am J Phys Anthropol, 1973, 39: 413-426

5 裴文中. 中国原始人类的生活环境. 古脊椎动物与古人类, 1960, 2: 9-21 
6 许春华, 韩康信, 王令红. 鄂西巨猿化石及其共生的动物群. 古脊椎动物与古人类, 1974, 12: 293-309

7 郑绍华. 建始人遗址. 北京: 科学出版社, 2004

8 Pilbeam D. The Ascent of Man, an Introduction to Human Evolution. New York: Macmillan publishing Co. Inc. 1972. 86-89

9 DeNiro M J, Epstein S. Influence of diet on the distribution of carbon isotopes in animals. Geochim Cosmochim Acta, 1978, 42: 495-506

10 Wang Y, Cerling T. A model of fossil tooth and bone diagenesis: Implications for paleodiet reconstruction from stable isotopes. Palaeogeogr Palaeoclim Palaeoecol, 1994, 107: 281-289

11 Lee-Thorp J A, van der Merwe N J. Carbon isotope analysis of fossil bone apatite. South Afr J Sci, 1987, 83: 712-715

12 Lee-Thorp J A, van der Merwe N J, Brain C K. Diet of Australopithecus robustus at Swartkrans from stable carbon isotopic analysis. J Hum Evol, 1994, 27: 361-372

13 Lee-Thorpe J A, Sponheimer M, Passey B H, et al. Stable isotopes in fossil hominin tooth enamel suggest a fundamental dietary shift in the Pliocene. Phil Trans R Soc B, 2010, 365: 3389-3396

14 Sponheimer M, Lee-Thorp J A. Isotope evidence for the diet of an early hominid, Austraolopithecus africanus. Science, 1999, 283: 368-370

15 Sponheimer M, Lee-Thorp J A, de Ruiter D, et al. Hominins, sedges, and termites: New carbon isotope data from the Sterkfontein valley and Kruger National Park. J Hum Evol, 2005, 48: 301-312

16 van der Merve N J, Masao F T, Bamford M K. Isotopic evidence for contrasting diets of early hominins Homo habilis and Australopithecus boisei of Tanzania. South Afr J Sci, 2008, 104: 153-155

17 van der Merwe N J, Thackeray J F, Lee-Thorp J A, et al. The carbon isotope ecology and diet of Australopithecus africanus at Sterkfontein, South African. J Hum Evol, 2003, 44: 581-597

18 Cerling T E, Mbua E, Kirera F M, et al. Diet of Paranthropus boisei in the early Pleistocene of East Africa. Proc Natl Acad Sci USA, 2011, 108: 9337-9341

19 Cerling T E, Harris J M, MacFadden B J, et al. Global vegetation change through the Miocene-Pliocene boundary. Nature, 1997, 389: $153-158$

20 Wang Y, Deng T. A $25 \mathrm{~m} . \mathrm{y}$. isotopic record of paleodiet and environmental change from fossil mammals and paleosols from th NE margin of the Tibetan Planteau. Earth Planet Sci Lett, 2005, 236: 322-338

21 Gaboardi M, Deng T, Wang Y. Middle Pleistocene climate and habitat change at Zhoukoudian, China, from the carbon and oxygen isotope record from herbivore tooth enamel. Quat Res, 2005, 63: 329-338

22 高建. 与鄂西巨猿共生的南方古猿牙齿化石. 古脊椎动物与古人类, 1975, 13: 81-88

23 Cerling T E, Harris J M. Carbon isotope fractionation between diet and bioaptite in ungulate mammals and implications for ecological and paleoecological studies. Oecologia, 1999, 120: 347-363

24 殷立娟, 李美容. 中国 $\mathrm{C}_{4}$ 植物的地理分布与生态学研究 I 中国 $\mathrm{C}_{4}$ 植物及其与气候环境的关系. 生态学报, 1997, 17: 350-363

25 Wang R Z. Natural occurrence and backwater infection of $\mathrm{C}_{4}$ plants in the vegetation of the Yangtze hydropower Three Gorges Project region. Photosynthetica, 2003, 41: 43-48

26 Ehleringer J R, Lin Z F, Field C B, et al. Leaf carbon isotope ratios of plants from a subtropical monsoon forest. Oecologia, 1987, 72: $109-114$

27 程捷, 高振纪. 植物狍粉与环境. 见: 郑绍华, 主编, 建始人遗址. 北京: 科学出版社, 2004. 338-349

28 Biasatti D, Wang Y, Gao F, et al. Paleoecologies and paleoclimates of Late Cenozoic mammals from southwest China: Evidence from stable carbon and oxygen isotopes. J Asian Earth Sci, 2011, doi: 10.1016/j.jseaes.2011.04.013

29 Ciochon R L, Piperno D R, Thompson R G. Opal phytoliths found on the teeth of Gigantopithecus blacki: Implications for paleodietary studies. Proc Natl Acad Sci USA, 1990, 87: 8120-8124

30 Daegling D J, Grine F E. Bamboo feeding, dental microwear, and diet of the Pleistocene ape Gigantopithecus blacki. South Afr J Sci, 1994, 90: 527-532

31 韩康信, 赵凌霞. 湖北巨猿牙齿齵病观察. 人类学学报, 2002, 21: 191-198

32 赵凌霞. 建始龙骨洞巨猿䶔齿研究. 见: 董为, 主编. 第十届中国古脊椎动物学学术年会论文集. 北京: 海洋出版社, 2006. 103-108

33 White T D, Asfaw B, Beyene Y, et al. Ardipithecus ramidus and the paleobiology of early hominids. Science, 2009, 326: 75-86

34 童国榜, 陈云, 吴锡浩, 等. 中国更新世环境巨变的狍粉植物群记录. 地质力学学报, 1999, 5: 11-21

35 Shumarker R W, Beck B B. Primates in Question. Washington and London: Smithsonian Books, 2003. 151-156

36 王应祥, 将学龙, 冯庆. 黑长臂猿的分布、现状与保护. 人类学学报, 2000, 19: 139-147

37 赵凌霞. 步氏巨猿牙齿化石的综合研究. 博士学位论文. 北京: 中国科学院研究生院, 2006 